ARTIGO

\title{
Multilateralismo e unilateralismo na política mundial: América Latina frente à Ordem Mundial em transição
}

RAÚL BERNAL-MEZA*

Rev. Bras. Polít. Int. 48 ( I): 5-23 [2005]

\section{Introdução}

O tema do multilateralismo e do unilateralismo na política mundial é fundamental para uma abordagem adequada da "agenda latinoamericana de política exterior”. Os países latino-americanos, caracterizados por sua fragilidade em termos de poder na estrutura de poder mundial, estão limitados, em grande medida, no que se refere às suas margens de autonomia de decisão internacional. Dependem da articulação de alianças e das negociações internacionais, do funcionamento de foros, instituições e regimes para poderem conseguir atingir alguns dos seus objetivos de política exterior vinculados ao desenvolvimento e à sua segurança. Essas possibilidades dependem, obviamente, da estrutura de poder existente, do papel representado e da posição adotada pela potência principal.

Os Estados Unidos têm enfrentado, desde o final de 1989, o desafio de encontrar uma forma para exercer a hegemonia global. A questão central para a potência tem sido a maneira de resolver o tema da liderança:

\footnotetext{
* Professor Titular de Relações Internacionais da Universidad Nacional del Centro da Província de Buenos Aires (Argentina) e professor da Universidade de Buenos Aires (bernalmeza@hotmail.com). Este artigo foi traduzido do espanhol por Ricardo Avelar.
} 
mediante o uso do multilateralismo ou do unilateralismo, na medida em que a agenda de política exterior norte-americana também se transforma em função das mudanças globais e transnacionais.

De acordo com vários autores ${ }^{1}$, responder as demandas dessa nova agenda supõe uma concepção mais ampla sobre o interesse nacional, levando em consideração que são poucos os problemas atuais que podem ser enfrentados unilateralmente e que a compreensão do papel do multilateralismo favorece a legitimação do poder norte-americano.

A guerra contra o Iraque, em 1991, permitiu ao poder norteamericano recuperar a sua credibilidade e sepultar a "síndrome Vietnã". Possibilitou a revitalização da credibilidade dos Estados Unidos e, sobre essa plataforma, Bush "pai" proclamou uma nova ordem mundial, baseada nos princípios de uma oposição inalterável à agressão.

Segundo Ambrose e Brinkley ${ }^{2}$, a doutrina Bush foi criticada no seu surgimento pelos analistas norte-americanos de política internacional, para os quais a nação norte-americana se encontrava sob o domínio de uma patologia, cuja essência era a nova atitude propensa ao uso da força. De acordo com eles: "criamos uma anarquia e chamamos isso de paz. Em nome da ordem fazem-se estragos. Permitimo-nos assumir um papel imperial”. Em uma escala menor, a intervenção no Panamá já havia revelado grande parte dessas características.

\section{A política exterior norte-americana após o 11 de Setembro}

Colocou-se em prática, a partir desses acontecimentos, uma reformulação ultraconservadora da política, dotada de uma ampla estratégia que abrangesse os âmbitos interno e externo. Em síntese, o que o império começou a considerar foi a possibilidade de exercer a democracia ao tempo em que tinha interesse em promovê-la, (ou impô-la) ao mundo.

No âmbito da sua política interna, o governo norte-americano começou a motivar a instauração de um sistema de direito que prescinde

\footnotetext{
1 PATRICK, Stewart and FORMAN, Shepard (Eds.), Multilateralism \& U.S. Foreign Policy. Ambivalent Engagement, Boulder, Co., Lynne Rienner Publishers, Inc, 2002.

2 AMBROSE, Stephen E. and BRINKLEY, Douglas G., Rise to Globalism,London, Penguin Books Ltd; eighth revised edition, 1997.
} 
a lei e as instituições democráticas (julgamento de suspeitos por tribunais militares, ampliação dos poderes policiais, escutas telefônicas e captação de comunicações feitas na internet, instauração de tribunais ad hoc, detenção e acusação com base em provas sigilosas, relativização de regras que controlam a entrada e atuação das agências de segurança (FBI) e ampliação de suas ações à espionagem interna sobre organizações políticas e religiosas estabelecidas no território dos Estados Unidos, etc.).

A reformulação conservadora da política exterior, como em outros períodos da história (tal qual a Doutrina de Contenção depois da Segunda Guerra Mundial), faculta a abertura de uma via de legitimação de políticas internas em outros países, onde pudessem ser aceitas limitaçóes democráticas em troca de um compromisso externo com a política global da potência.

George Bush Jr. enunciou três princípios daquilo que ele convencionou como "nova política exterior". Isso é o que diversos autores denominaram como princípios das guerras preventivas.

1) $O$ primeiro princípio representa o fim do direito à neutralidade, fundamentado no conceito de que "quem não estiver com os Estados Unidos está com os terroristas e com os Estados que os amparam".

2) O segundo considera a legitimação da idéia de "ataque preventivo" para responder às ameaças. O problema é que essas ameaças podem ser reais, supostas ou, simplesmente, inventadas.

3) O terceiro aborda o direito de utilizar "todas as armas", o que possibilita o uso tanto das convencionais, como das não convencionais (biológicas, químicas e atômicas).

A "novidade" da política internacional dos Estados Unidos reflete o interesse norte-americano de empregar todo o poder da sua hegemonia sem nenhum tipo de controle externo ou internacional. A superpotência se isolou dos seus sócios tradicionais no âmbito internacional e entrou em conflito político com eles. Foi possível evidenciar isso pelas posições adotadas no Conselho de Segurança, pela fratura dentro da Otan (Alemanha e França) e pelo relacionamento no escopo da Nafta (Canadá e México). 


\section{O contexto de análise para avaliação do multilateralismo e do unilateralismo nas agendas globais}

O período posterior à guerra fria caracterizou-se pelo fato da democracia e do livre mercado ocuparem novos espaços, mesmo que o aumento da interdependência global tenha criado novos e diversos problemas. Para os EUA o avanço dos princípios liberais e o surgimento de uma agenda global poderiam conduzir a diversas opções políticas. Em temos gerais, parecia lógico que o multilateralismo oferecesse o melhor caminho para a conquista dos seus "objetivos nacionais", para a promoção de objetivos comuns e o exercício de uma liderança aceita.

Pode-se inferir que desde Clinton até o 11 de Setembro a política norte-americana havia assumido um compromisso ambivalente com o multilateralismo. Esse "compromisso ambivalente" nem sempre se expressou de maneira direta - em outras palavras, uma clara opção pelo unilateralismo - inclusive às vezes lançou mão de métodos e práticas como o não cumprimento das quotas de financiamento da $\mathrm{ONU}$, a manutenção do boicote a determinados organismos (como a Unesco), a aplicação de sanções extraterritoriais (Iran-Libia Sanctions Act, Lei Helms-Burton) ou a não ratificação de Convenções Internacionais, aduzindo o princípio da autonomia de seus poderes nacionais (Congresso).

Apesar de haver uma manifestação clara de poder sob a ótica do realismo, que é a que se impõe como visão dominante, a maior fonte de expressão - como oposição ao multilateralismo - tem sido o próprio Congresso norte-americano. Entretanto, essa tem sido uma posição que, em geral, não é compartilhada pela sociedade americana. Prevalece a percepção externa de que os Estados Unidos atuam sozinhos e de maneira unilateral, atitudes que têm aumentado desde 2001.

Segundo a opinião do mundo acadêmico (do Center on International Cooperation da Universidade de Nova Iorque, por exemplo) o multilateralismo é muito mais valioso para os Estados Unidos, tanto para alcançar os seus objetivos de "interesse nacional", como para manter a sua liderança.

Os acontecimentos, desde a invasão e a vitória no Iraque, apontam para algumas teses que aumentam a capacidade de antever o que pode continuar acontecendo mais adiante: 
1) a impossibilidade de se conter um poder que se tornou incontrolável;

2) a decisão do governo Bush de não aceitar o controle de regimes internacionais criados e estimulados pelo seu próprio país, tais como as Nações Unidas, a Otan, o Tribunal Penal Internacional, etc;

3) que Estados Unidos e alguns dos seus aliados próximos decidam que podem substituir os governos dos Estados soberanos de forma aberta. $\mathrm{Na}$ realidade, os Estados Unidos sempre fizeram isso, mas de maneira subliminar (caso do Chile, Bolívia, América Central, etc.);

4) o desprezo pela democracia. Na prática - se a democracia é respeitada - ela se expressa, internamente, no respeito à opinião dos cidadãos de cada país e, internacionalmente, no respeito à vontade dos Estados nas Naçōes Unidas e nas agendas mundiais. O governo republicano dos Estados Unidos tem optado por desprezar tanto a opinião dos cidadãos quanto a vontade dos governos.

Em síntese, a nova hegemonia, ao reformular as políticas da ordem mundial, está influenciando, em longo prazo, a variável "suave" da política, entendida como valores, sistemas de crenças, percepções, a formação de governantes e - talvez o mais grave - o tipo de regime político.

\section{Perigo do unilateralismo}

Para os países pequenos, essa atitude limita de forma decisiva as suas margens de ação e a sua autonomia relativa para adotar posições contrárias à definição do interesse específico dos Estados Unidos e enfraquece a sua capacidade de estabelecer alianças. Para os países médios e grandes, o efeito gera resistências além da vontade de optar pela imitação desse procedimento, mediante o qual uma gama de fatores atrelados à legitimidade internacional perde espaço. Em geral, compreende-se que o multilateralismo dá suporte à estabilidade democrática dos países em desenvolvimento. 
Ao abordar o impacto dessa questão, John Ikenberry ${ }^{3}$, discute a visão segundo a qual os defensores do multilateralismo são utópicos, afirmando que o apoio ao multilateralismo foi um êxito na grande estratégia norteamericana desde 1945. O autor defende que os países fracos só estão dispostos a seguir a liderança norte-americana porque eles possuem um grau aceitável de certeza de que os Estados Unidos não explorarão a sua posição de poder nem desistirão de cumprir as suas obrigaçóes, isso em um contexto onde as instituições multilaterais assumem, hoje, mais importância que no passado para os Estados Unidos e para a sua grande estratégia global. Como é possível evidenciar, são justamente essas questóes que estão em jogo e enfraquecem a credibilidade internacional dos Estados Unidos em seu compromisso pela paz, pela segurança, pela estabilidade, pela democracia e pelo desenvolvimento.

\section{Agendas ou áreas temáticas da ação unilateral e do multilateralismo ambivalente}

É evidente que, quando se fala de “agenda internacional”, é obrigatório se fazer menção a todas aquelas instituições e regimes a partir dos quais - e sobre a base de negociações multilaterais (ou plurilaterais, quando se trata de um grupo "seleto de Estados") - os acordos são estabelecidos, acordos que restringem a soberania dos Estados em benefício de uma cooperação mais ampla em outros campos.

Desse ponto de vista, o escopo das Nações Unidas e de seus diversos organismos é aquele que - historicamente, desde 1945 - estimulou a realização de acordos e negociações para a criação de regimes de forma mais intensa. Contudo, as coisas mudariam radicalmente a partir do fim da guerra fria. Como indicam Stephen Ambrose e Douglas Brinkley, "em um mundo com uma única superpotência, as Nações Unidas não poderiam desempenhar um papel proeminente sem a liderança dos EUA". ${ }^{4}$

O multilateralismo ambivalente hoje é evidenciado, assim, nas agendas das Nações Unidas nas "operações de paz", nas negociações sobre testes nucleares, na convenção sobre armas químicas, nas agendas

3 John Ikenberry, "Multilateralism and U.S. Grand Strategy", en PATRICK, Stewart and FORMAN, Shepard, op. cit., p. 121-140.

${ }^{4}$ AMBROSE, Stephen E. and BRINKLEY, Douglas G., op. cit., p. 384. 
financeiras (FMI) e de comércio (OMC), perante o Tribunal Penal Internacional, nas negociações sobre mudanças climáticas, etc.

\section{O contexto hemisférico e mundial e a sua influência sobre a política exterior latino-americana ${ }^{5}$}

Ainda que pareça paradoxal - diante das profundas transformações do sistema mundial - hoje o tema predominante da agenda de política exterior latino-americana é a Alca.

A análise sobre os diversos aspectos que envolvem a discussão em torno da solidificação desse projeto comercial norte-americano - e para o caso particular dos países latino-americanos - deve ter como ponto de partida uma interpretação realista ${ }^{6}$ dos contextos nos quais as negociações se desenvolvem. De maneira sintética, poderíamos evidenciar pelo menos seis características do atual sistema mundial que determinam as margens de manobra ou de ação dos países latino-americanos no âmbito da política mundial:

1) A globalização, como processo identificador da atual etapa do sistema mundial, é o espaço de exercício de todas as manifestações de poder.

2) Encontramo-nos diante de um poder hegemônico global sem precedentes na história. Os Estados Unidos reúnem maiores capacidades em termos militares, político-diplomáticos, econômicos, financeiros, científicos e tecnológicos do que qualquer outro Estado ou conjunto de Estados em federação;

3) apesar disso, não podemos afirmar que uma "nova ordem mundial” já esteja em processo de imposição como estrutura sistêmica. Essa "nova ordem" ainda está em fase de construção e os seus delineamentos não estão ainda claramente definidos.

4) Os Estados Unidos, após a obtenção do seu triunfo na Guerra Fria, continuaram com uma capacidade de reconstrução

\footnotetext{
${ }^{5}$ Analisamos extensamente a evolução do sistema mundial, desde o fim da Guerra Fria, em três dos nossos livros; cfr. BERNAL-MEZA, Raúl (1991; 1994 e 2000).

${ }^{6}$ Não falamos aqui do paradigma clássico de Relaçōes Internacionais e maior expressão da "Escola Norte-americana", mas de uma perspectiva sustentada na evidência objetiva dos fenômenos político-sociais.
} 
econômica, científica, tecnológica, comercial e financeira, que o colocaram acima de qualquer outro competidor. Como resultado, houve uma polarização da desigualdade entre os Estados Unidos e a América Latina, que se agrava em função do novo período de crise econômica, política e social pela qual passa a maioria dos países latino-americanos.

5) O sistema mundial depara os países da América Latina com riscos e desafios, derivados dos cenários anteriores. Esses desafios, traduzidos em "tensões globais" (segurança, comércio, finanças) põem de manifesto uma realidade: a América Latina tem uma capacidade de intervenção muito marginal diante dessas tensões globais;

6) ainda assim, pode ter uma capacidade decisiva na construção da Alca.

Tendo presente, então, esse cenário e devido às condições políticas e econômicas da ordem mundial, podemos afirmar que a Alca é hoje o tema internacional mais importante da agenda latino-americana. Ao mesmo tempo, é um tema debatido e de alto teor de controvérsia, tanto entre os governos, como no interior das sociedades nacionais. Isso se explica pelas características sistêmicas enumeradas e em função das motivações, interesses e interpretações associadas que têm uma influência significativa, derivações do longo passado histórico de relações profundamente tendentes ao conflito e divergentes entre os Estados Unidos e a América Latina.

Em algumas das importantes agendas temáticas que preocupam os países latino-americanos, o compromisso ambivalente da superpotência apresenta um traço tendente ao conflito e, no contexto da construção da Alca, o compromisso ambivalente é visto como ausência ou escassez de uma vontade real de negociação multilateral no nível hemisférico.

A evolução da economia mundial, em fase de globalizaçãomundialização ${ }^{7}$ e o papel que os Estados Unidos estão assumindo no

\footnotetext{
7 Segundo a nossa caracterização, que combina os aspectos políticos e ideológicos (incluindo a visão do que foi imposto como "globalização") com as características do capitalismo mundial (concentração oligopólica, cartelização, predominância do capital financeiro sobre o produtivo e industrial, etc.); cfr. Raúl BERNAL-MEZA, Sistema Mundial y MERCOSUR, Buenos Aires: Grupo Editor Latinoamericano, 2000.
} 
cenário político e no econômico (Nações Unidas, OMC, FMI, Banco Mundial), ameaçam as perspectivas da democracia latino-americana. A política da administração Bush não está colaborando para a construção de um bloco de forças que permita a articulação adequada para o fortalecimento da democracia com o crescimento econômico, o desenvolvimento integral ${ }^{8}$ e uma redistribuição mais eqüitativa da renda na América Latina.

Os Estados Unidos e a América Latina têm uma visão distinta sobre a raiz dos problemas do desenvolvimento. Para Washington, os fundamentos dos problemas latino-americanos são mais políticos e institucionais que econômicos (como corrupção, ineficiência, falta de uma legislação que defenda e proteja o capital, etc.) Para a América Latina, os problemas são essencialmente econômicos e se vinculam às condições estruturais da economia e do comércio internacionais ?

\section{A visão sobre a Segurança e o problema do poder no hemisfério}

Esse é o segundo cenário de desencontros nesse âmbito. Durante os anos 90, a maioria dos governos latino-americanos optou por uma visão kantiana das relaçooes internacionais, que se evidenciou na aplicação de políticas neoliberais, na aceitação do "Consenso de Washington" e em uma tendência para a abertura econômica e política. ${ }^{10}$

Entretanto, a situação de crise econômica, social e política que se deu em quase toda a América Latina (cujos exemplos, hoje, estão presentes na situação da Bolívia, Argentina, Paraguai, Peru, etc.) mostrou que nossos

\footnotetext{
${ }^{8}$ Cfr. HEINE, Jorge (2002), ¿¿Qué pasó, Tío Sam? Los Estados Unidos y América Latina después del 11 de septiembre", In: Estudios Internacionales, Santiago: Instituto de Estudios Internacionales de la Universidad de Chile, Año XXXV, julio-septiembre 2002, Nº 138, p. 89-106.

9 Ver, Andrés Oppenheimer, Claves americanas. La pobreza, el nuevo lema de Washington. Diario La Nación, Buenos Aires, 16 de setembro de 2003, p. 2.

${ }^{10}$ Cfr. CERVO, Amado Luiz (2000) Sob o signo neoliberal: as relaçôes internacionais da América Latina. Revista Brasileira de Politica Internacional, Ano 43, № 2, 2000; Brasília, Instituto Brasileiro de Relaçôes Internacionais, p. 5-27. Relaçôes internacionais do Brasil: a era Cardoso. Revista Brasileira de Politica Internacional, Ano 45, No 1, 2003, Brasília, Instituto Brasileiro de Relaçōes Internacionais, , p. 5-35, "Política exterior brasileña 1990-2003", In: Mesa Redonda “Cambios en las politicas exteriores de América Latina", VII Jornadas de Historia de las Relaciones Internacionales. América Latina frente al poder global: Crisis y Desafios. Del Siglo XIX a nuestros días; Asociación Argentina de Historia de las Relaciones Internacionales, CEILA e Instituto de Investigaciones de Historia Económica y Social de la Facultad de Ciencias Económicas de la Universidad de Buenos Aires; Buenos Aires, 22 al 24 de octubre de 2003.
} 
países tiveram que deparar-se com o poder e seu impacto na economia, na política, nas finanças e no comércio internacional, situação que não puderam resolver de maneira favorável até o presente.

A partir das mudanças de governo, ocorridas nos três últimos anos, em particular no Brasil, mas também na Argentina e em outros países (como já há algum tempo no caso venezuelano), é possível perceber que uma avaliação da opção pelo "realismo de poder" na política exterior vem se instaurando. Contudo a avaliação sobre uma quantificação dessa opção, em termos de alianças, concerto/coordenação de agendas políticas e econômicas é bastante complexa, visto que os principais eixos da mesma (negociações da Alca e o fortalecimento do Mercosul) não apresentaram mudanças significativas em relação ao que acontece no início do novo século.

\section{As relações intralatino-americanas}

Apesar das manifestações de unidade, das manifestações de política de poder, da aspiração manifesta de alguns governos para a criação um bloco de poder (restrito à América do Sul ou ao Cone Sul), da limitação de conflitos no âmbito do Atlântico Sul e da cooperação política, seria ingênuo pensar que hoje a região latino-americana apresenta uma visão homogênea sobre o que deve ser a sua inserção internacional, sobre as suas relações com os Estados Unidos assim como sobre os temas de interesse para a superpotência (tais como nos casos pontuais de Cuba, Colômbia e Venezuela; a agenda de segurança, entre outros) e sobre a construção da Alca.

Pode parecer contraditório, mas a minha opinião é que - em comparação com outros momentos da história latino-americana, como durante a criação da Cepal, o "Consenso de Viña del Mar" (1969) ou, também, em esforços mais limitados geográfica e politicamente, tal como o Grupo de Contadora (1983) - hoje, como poucas vezes na história regional, ao definirem as suas respectivas inserçóes hemisféricas e mundiais, os países da América Latina têm muito poucos elementos políticos que sirvam para unir os diversos países. Essa situação é, portanto, um elemento relevante para abordar uma eventual agenda de convergência/ concertação e cooperação política no nível regional, vis-à-vis os Estados Unidos e o processo de construção da Alca. 
Quais são as razões dessas profundas diferenças? As suas origens são em parte externas e em parte internas à região. No primeiro caso, a política externa norte-americana, ao empregar a lógica de prêmio e castigo além de uma visão realista de poder, de dividir para reinar, contribuiu para distanciar os países latino-americanos entre si. Por um lado, existem aqueles que convergem com a potência na sua política comercial - como o Chile; de outro lado vêem-se aqueles que apresentam discrepâncias, como o Brasil, a Venezuela e a Argentina. Há também aqueles que compartilham algum nível de acordos políticos sobre segurança e/ou de aliança militar como a Colômbia e, em parte, o Chile e Argentina, versus aqueles países que Washington vê como opositores, tais como o Brasil e a Venezuela.

A respeito do posicionamento com relação à Alca, há aqueles a desejam, como os da América Central, Colômbia, Peru e Equador, aqueles a quem não interessa a Alca, em especial, porque já têm o seu próprio acordo de livre comércio com os Estados Unidos e acreditam que perderiam algumas das vantagens adquiridas, como México e Chile e, por último, aqueles que vêem na Alca um perigo potencial para as suas economias, como a Argentina e, fundamentalmente, o Brasil.

Da mesma forma, no âmbito das linhas gerais do hemisfério, percebem-se fatores que, a partir de diversos ângulos da política, parecem estar criando dois eixos de liderança na região, um conduzido pelos Estados Unidos que inclui a Colômbia, o México e o Chile, e outro integrado pelo Brasil, Venezuela e Cuba. A linha de separação entre esses dois eixos são justamente as relações de cada país com os Estados Unidos, as posições a respeito dos projetos hemisféricos de Washington na economia, na segurança e nas relações com Cuba. Por exemplo, embora o Chile tenha se oposto aos Estados Unidos no Conselho de Segurança das Nações Unidas na questão do Iraque, esteve do lado dos norte-americanos no questionamento a Cuba a respeito de direitos humanos e se opôs à recente proposta brasileira de incorporar o país caribenho ao Grupo do Rio, caminho que perceptivelmente poderia conduzir à reintegração de Cuba à OEA. ${ }^{11}$

\footnotetext{
${ }^{11}$ Ver a respeito o Diario La Tercera, Santiago de Chile, 22 de agosto de 2004: Fracasa propuesta para incorporar a Cuba al Grupo de Río, p. 13.
} 
O terceiro fator está agregado aos anteriores se levarmos em conta a renovação do compromisso de "aliança estratégica" que os presidentes do Brasil e da Argentina assinaram em Buenos Aires, durante a visita do presidente Lula da Silva, na medida em que a leitura que se faz da mesma aliança é muito diferente em governos como os da Venezuela e do Chile. Por último, há as percepções sobre o intervencionismo norte-americano na Colômbia, na Venezuela e a posição a respeito de Cuba, sobre a qual os países latino-americanos, ainda que em geral sejam contrários, divergem sobre a importância que dão a ela em suas respectivas políticas exteriores. Nesse último caso, o tema da condenação da ilha pela sua política interna vai desde as posiçóes contrárias até a abstenção e a adesão à posição adotada pelos Estados Unidos.

Ainda assim, no contexto interno latino-americano, podem-se observar dois fatores centrais geradores de diferenças:

1) a posição de liderança do Brasil, que gera desconfianças e receios nos países medianos como a Argentina e o Chile, fato que está provocando a criação de alianças, como a existente entre o Chile e o México, no Conselho de Segurança, quando o Brasil e a Argentina, os dois maiores sócios, não apresentaram uma voz definida em torno do conflito no Iraque e sobre a intervenção norte-americana e de seus aliados, Grã-Bretanha - e naquela época - a Espanha.

É evidente que o Brasil, sob o governo do presidente Lula, está tornando mais aguda a sua opção pela liderança regional. ${ }^{12}$ As manifestações disso são múltiplas; para destacar apenas algumas: a declaração do seu desejo de ser incorporado como membro permanente do Conselho de Segurança da ONU; o aprofundamento dos vínculos políticos, econômicos e de infra-estrutura com os países do Grupo Andino; a proposta do "grupo de amigos", para resolver a crise interna na Venezuela; a proposta de colocar o território brasileiro à disposição das negociações entre o governo colombiano e as Farc, no marco das Naçôes Unidas; a posição de liderança diante das negociaçōes da Alca na última reunião de Puerto Espanã (3 de outubro de 2003); a liderança na formação do "Grupo dos 22" na reunião da OMC em Cancum; a posição eqüidistante aos Estados Unidos diante das situações internas

${ }^{12}$ Cfr. BERNAL-MEZA, Raúl (2003). 
da Venezuela e Cuba; o aprofundamento da cooperação estratégica (científico-tecnológica) com a China; a recente proposta para a incorporação de Cuba ao Grupo do Rio; etc.

Essa liderança incomodou claramente o governo chileno, cuja posição provocou, por sua vez, desentendimentos com o Brasil e aborrecimento no governo do presidente Lula da Silva. O Brasil interpretou a posição chilena - nesse aspecto assim como nos outros temas mencionados como uma competição pela liderança, embora, nas últimas semanas, o governo chileno tenha dado alguns passos revendo a sua posição, declarando que "o interlocutor natural dos Estados Unidos na América do Sul é, pela sua dimensão, o Brasil”, ao mesmo tempo em que a adiada visita de Lula a Santiago concretizou-se no dia 23 de agosto, a primeira visita oficial do governante brasileiro depois de um ano e nove meses de presidência.

2) O segundo fator se encontra no interior do próprio Mercosul. Aqui, por um lado, subsistem percepções acerca do interesse do Brasil em utilizar o bloco como um elemento de uma política de poder vis-à-vis os Estados Unidos e, por outro lado, as dificuldades entre a Argentina e o Brasil para reforçar o Mercosul. ${ }^{13}$

Tanto a Argentina quanto o Brasil deixaram de manifesto, reiteradamente, que a negociação da Alca deve dar-se depois do aprofundamento do Mercosul. O elemento contraditório é que o tema fundamental da agenda da Alca - e em relação ao qual o Brasil tem sido parcimonioso em iniciar as negociações - são os serviços e como se liberará o comércio ao generalizar-se uma eventual Alca hemisférica, ao mesmo tempo em que, no Mercosul, não existe ainda nada que se aproxime de uma agenda de negociações para o setor.

Mesmo depois da última reunião de Miami, a Argentina e o Brasil têm mantido divergências importantes em torno do quê, como e quando negociar a Alca. A proteção aos investimentos estrangeiros e os serviços continuam sendo os pontos de discrepância. Para a Argentina, o tema da proteção dos investimentos estrangeiros pode ser uma "garantia de negociação com os Estados Unidos”, na medida em que Washington

13 Para uma visão ampla das convergências e divergências entre os sócios do Mercossul, $c f r$. BERNAL-MEZA, Raúl (2000 e 2002). 
esteja disposto a negociar concessões para produtos industriais e agrícolas; o Brasil, por outro lado, não está disposto a colocar nas mãos dos norte-americanos um condicionamento á autonomia em matéria de política econômica. Enquanto a Argentina, por sua parte, assinou 52 acordos bilaterais de proteção aos investimentos estrangeiros durante os anos 90 (presidência de Menem), o Brasil nunca aceitou esse tipo de instrumentos. ${ }^{14}$ Esses temas e a dinâmica que ambos os sócios do Mercosul querem dar à negociação expressam divergências mais profundas, as quais não só devem vincular-se às necessidades de recomposição das economias internas e a recuperação do crescimento (muito mais grave no caso argentino), mas também o interesse que ambos têm em uma aproximação aos Estados Unidos além do desejo de serem considerados como o seu mais importante interlocutor regional.

Nesse sentido, a política exterior argentina não mudou desde os tempos de Menem e continua dando mostras da sua simpatia para Washington, simpatia que abrange alguns temas importantes da agenda de segurança, como a percepçáo sobre o conflito colombiano e a continuidade das operações e exercícios militares conjuntos. Paradoxalmente, ao mesmo tempo, o Chile, o Brasil e a Argentina estão participando da missão internacional no Haiti, quando, nos dois últimos países, sempre existiu a convicção de que os Estados Unidos intervieram abertamente nesse pequeno país e depuseram o então presidente Aristide.

Apesar dos progressos alcançados em termos comerciais e de segurança no âmbito do Atlântico Sul e do Cone Sul, das declaraçóes sobre a sua aliança estratégica e dos sólidos vínculos que têm se criado entre as sociedades dos dois grandes países, o Brasil e a Argentina ainda não têm uma política clara e definida em relação ao Mercosul, importante para que os sócios menores (e também aqueles países que vêem o Mercosul com interesse em uma futura integração) possam assumir nele um grau de previsibilidade que o torne um destino seguro para os seus compromissos. ${ }^{15}$

\footnotetext{
${ }^{14}$ Ver, Clarín, Alca: desacuerdos sobre cómo negociar; Buenos Aires 16 de diciembre de 2003, p. 14.

${ }_{15}$ Desenvolvemos uma revisão dos progressos e fragilidades do Mercosul em diversos estudos recentes; cfr. BERNAL-MEZA, Raúl (2000; 2002 e 2002ª).
} 
A Argentina e o Brasil mostraram o Mercosul apenas como uma união aduaneira, um acordo comercial. Isso é o que falta mudar, mas requer a resolução prévia do problema da liderança brasileira e da sua decisão de ser incorporado como membro permanente do Conselho de Segurança da ONU, tema ao qual a Argentina se opõe abertamente.

O Mercosul precisa gerar uma percepção sobre a Segurança e também mostrar uma disposição em assumir responsabilidades diante de situaçōes eventuais que possam dar-se, tal como ficou evidente pela ação dos governos de Brasília e Buenos Aires atuando conjuntamente no auxílio à resolução da crise institucional da Bolívia que levou à renúncia do presidente Sánchez de Lozada.

Entretanto, os avanços não devem ser desprezados. Há uma oportunidade no Cone Sul para que os seus membros, os sócios principais do Mercosul, tenham uma visão comum dos problemas regionais e mundiais, sobre como enfrentá-los e como podem melhorar a sua participação na construção da nova ordem mundial.

\section{Conclusões}

Existem diferenças significativas que separam os Estados Unidos e a América Latina, tanto em temas políticos como econômicos no nível hemisférico e em um contexto de hegemonia global. Evidencia-se a inexistência de uma "agenda comum" porque os conteúdos das agendas próprias aos atores diferem substancialmente uns dos outros.

Contudo, apesar de estarmos na presença de um poder hegemônico global sem precedentes na história e do fato que os Estados Unidos, graças à sua reestruturação econômica positiva, tenham incrementado a polarização da desigualdade entre ambas as partes, Washington está começando a enfrentar manifestações de "políticas de poder", que buscam contrabalançar o seu peso na região. A demonstração mais evidente e recente disso se expressa pelo reconhecimento que os Estados Unidos tiveram de dar à posição liderada pelo Brasil, aceitando-a, além de iniciar negociaçõos com o Mercosul sob o formato 4+1, fato que se agrega às manifestaçóes anteriores, como a posição adotada pelo Chile e pelo México no Conselho de Segurança ao discutir-se ali a política da Organização sobre o Iraque e a predisposição de alguns governos 
sul-americanos em encontrar opções próprias para resolver as crises político-institucionais.

Os Estados Unidos não se mostraram como um ator político que facilite a união das Américas. Com suas políticas, ele tendeu mais à fragmentação do cenário regional e hemisférico. Essa posição histórica foi reiterada no contexto do processo da Alca.

Levando em consideração, portanto, o cenário definido pelo acordo recente realizado em Miami, são identificados pelo menos quatro problemas globais de segurança que, da perspectiva latino-americana criam riscos para a construção de uma Alca mais ambiciosa. Obviamente, esse cenário de problemas para a região vai muito mais além da Alca, mas a área como ponto de referencia se explica uma vez que atualmente a Alca é o tema exclusivo da agenda latino-americana.

1) O perigo de uma democracia sem justiça social. A democracia latino-americana é debilitada pela existência de sistemas políticos corruptos e pela continuidade do modelo econômico liberal.

2) Os riscos do novo intervencionismo norte-americano, que está caracterizado pelas suas condutas unilaterais, além do impacto dessa posição no marco das negociações multilaterais. Tanto nas negociações multilaterais globais, na política e segurança, no comércio, e nos temas da "nova agenda" (meio ambiente, narcotráfico, migrações), quanto nas negociações hemisféricas de comércio (Alca) e narcotráfico, Washington deixou de lado a visão do internacionalismo liberal, debilitando a vinculação entre democracia, abertura econômica e reformas estruturais.

3) A ausência de projetos conjuntos que fortaleçam a unidade hemisférica. A Alca é um projeto norte-americano cujos objetivos não estão claros: se é apenas um projeto hegemônico para enfrentar os avanços da União Européia na região, se é um projeto para manter a hegemonia sobre o conjunto da região ou se só objetiva destruir os projetos de autonomia sul-americanos, como o Mercosul.

Em síntese, a política exterior latino-americana enfrenta, assim como a sua inserção na configuração da atual ordem em transição, grandes desafios. Sua resolução definitiva, em médio prazo, dependerá das 
capacidades dos governantes nacionais de impor uma agenda concertada de políticas que lhe permitam uma maior margem de negociação, tanto no nível hemisférico - vis-à-vis os Estados Unidos - como no nível global, visto que a experiência histórica indica que as opções individuais pela reduzida capacidade de influência e poder dos países da região, são arriscadas e ineficientes. Entretanto, as diferenças existentes entre os próprios países da região, a respeito da construção da Alca, do fortalecimento da integração no Cone Sul, das relações com os Estados Unidos, etc., estão atuando também em sentido contrário.

Recebido em 22 de setembro de 2004 Aprovado em 15 de janeiro de 2005

\section{Referências Bibliográficas}

AMBROSE, Stephen E. and BRINKLEY, Douglas G., Rise to Globalism,London, Penguin Books Ltd; eighth revised edition. 1997.

BERNAL-MEZA, Raúl. Claves del Nuevo Orden Mundial. Buenos Aires: Grupo Editor Latinoamericano, 1991.

- América Latina en la Economía Política Mundial, Buenos Aires: Grupo Editor Latinoamericano, 1994.

. Sistema Mundial y Mercosur. Globalización, Regionalismo y Políticas

Exteriores Comparadas, Buenos Aires: Grupo Editor Latinoamericano/ Nuevohacer y Universidad Nacional del Centro de la Provincia de Buenos Aires, 2000.

. Os dez anos de Mercosul e a crise Argentina. Politica Externa, Vol. 10, N 4, março-abril.maio 2002; p. 7-46. Sâo Paulo: Editora Paz e Terra/ Gagint-USP-Universidade de Sâo Paulo/Instituto de Estudos Econômicos e Internacionais.

. “Latin American Integration: Regionalism or Globalisation?”, In: Suranjit Kumar Saha and David Parker (Eds.), Globalisation and Sustainable Development in Latin America. Perspectives on The New Economic Order, Montpellier Parade, Cheltenham (UK), Edward Elgar Publishing Limited, 2002; p. 153-173. 
"Politica exterior de Argentina, Brasil y Chile 1990-2003.Perspectiva comparada", In: José Flavio Sombra Saraiva (editor), Foreign Policy and Political Regime, Brasília: Instituto Brasileiro de Relaçôes Internacionais, Universidade de Brasilia, 2003; p. 237-276.

CERVO, Amado Luiz. Sob o signo neoliberal: as relaçôes internacionais da América Latina, Revista Brasileira de Politica Internacional, Brasília, Instituto Brasileiro de Relaçôes Internacionais, Ano 43, No 2, 2000; p. 5-27.

. Relaçôes internacionais do Brasil: a era Cardoso, Revista $B$ rasileira de Política Internacional, Ano 45, No 1, 2002; p. 5-35. Brasília: Instituto Brasileiro de Relaçōes Internacionais,

. "Politica exterior brasileña 1990-2003", en Mesa Redonda "Cambios en las políticas exteriores de América Latina”, VII Jornadas de Historia de las Relaciones Internacionales. América Latina frente al poder global: Crisis y Desafíos. Del Siglo XIX a nuestros días, organizado por la Asociación Argentina de Historia de las Relaciones Internacionales, el CEILA y el Instituto de Investigaciones de Historia Económica y Social de la Facultad de Ciencias Económicas de la Universidad de Buenos Aires; Buenos Aires, 22 al 24 de octubre de 2003.

HEINE, Jorge (2002), “Qué pasó, Tío Sam? Los Estados Unidos y América Latina después del 11 de septiembre", In: Estudios Internacionales, Santiago: Instituto de Estudios Internacionales de la Universidad de Chile, Año XXXV, julio-septiembre 2002, N 138, p. 89-106.

PATRICK, Stewart and FORMAN, Shepard (Eds.) Multilateralism \& U.S. Foreign Policy. Ambivalent Engagement, Boulder, Co., Lynne Rienner Publishers, Inc, 2002.

\section{Resumo}

No artigo se analisa a evolução da situação da América Latina no sistema internacional no início do século XXI. Traça, primeiramente, linhas panorâmicas sobre a configuração da ordem mundial subseqüente à guerra fria e sobre o impacto que as mudanças na política exterior norte-americana exerceram sobre o multilateralismo e o unilateralismo. Em segundo lugar avaliam-se as formas pelas quais esses impactos reverberaram na inserção internacional da América Latina. Procura-se, em seguida, listar e avaliar as mudanças introduzidas pelos Estados Unidos no exercício da sua política internacional após o 11 de Setembro. 


\section{Abstract}

The article analyses the evolution of the Latin America status in the international system in the early $21^{\text {th }}$ Century. After a panoramic view considering the world order setting after the cold war and the impact that the changes on the American foreign politics had on multilateralism and on unilateralism, it analyses the effects on the international insertion of Latin America. The article also endeavors to name and evaluate the changes introduced in the international politics by the United States after the September, $11^{\text {th }}$.

Palavras-chave: Multilateralismo, Unilateralismo, Estados Unidos, América Latina, Alca.

Key words: Multilateralism, Unilateralism, United States, Latin America, AFTA. 